HIFAN 1765

\title{
HIFS VNL Monthly Progress Report Preparation for NDCX-II Project
}

\author{
Grant Logan - NDCX-II mission and constraints \\ Joe Kwan - Project overview, desired beam, acceptance goals, issues \\ John Barnard - Target physics for NDCX-II \\ Matthaeus Leitner - Project plan \& engineering implications \\ Alex Friedman - Physics design \\ Joe Kwan - Ion source \\ [Visit B58 test stand, NDCX-I, future site of NDCX-II] \\ Erik Gilson - Neutralized drift line \\ Matthaeus Leitner - alignment and assembly \\ Will Waldron - Pulsed power and other EE \\ Frank Bieniosek - Beam diagnostics
}

Accelerator Fusion Research Division

Ernest Orlando Lawrence Berkeley National Laboratory

University of California

Berkeley, California 94720

May 2009

This work was supported by the Director, Office of Science, Office of Fusion Energy Sciences, of the U.S.

Department of Energy under Contract No. DE-AC02-05CH11231. 
May 29, 2009

\section{HIFS VNL Monthly Progress Report}

\section{Preparation for NDCX-II Project}

In preparation for the project and for anticipated review in August, the HIFS-VNL hosted an NDCX-II Advisory Meeting at LBNL on May 27, 2009. A number of experts in accelerator physics, engineering, and construction were asked to visit for a full day, listen to presentations on the project, its goals, and its status, and to offer their advice on how best to proceed, what topics needed attention, and what technical options seemed most attractive to them. This was a productive meeting, and the Committee's comments will provide useful guidance. The presentations, and the members of the Advisory Committee, were:

Presentations:

Grant Logan - NDCX-II mission and constraints

Joe Kwan - Project overview, desired beam, acceptance goals, issues

John Barnard - Target physics for NDCX-II

Matthaeus Leitner - Project plan \& engineering implications

Alex Friedman - Physics design

Joe Kwan - Ion source

[Visit B58 test stand, NDCX-I, future site of NDCX-II]

Erik Gilson - Neutralized drift line

Matthaeus Leitner - alignment and assembly

Will Waldron - Pulsed power and other EE

Frank Bieniosek - Beam diagnostics

[Advisory group discussion and presentation of advice]

Committee:

Roger Bangerter

Dick Briggs

George Caporaso

Yu-Jiuan Chen (cancelled due to illness)

Andy Faltens

Larry Grisham (via phone)

Ed Lee

Daniela Leitner

Lou Reginato

Joseph Rasson

John Staples

Simon Yu (via internet) 


\section{NDCX/WDM/Advanced Theory and Simulations}

Eleven members of the HIFS-VNL attended the 2009 Particle Accelerator Conference in Vancouver, Canada, May 4-8, 2009. At the conference, members of the VNL presented three invited presentations on our recent advances in the NDCX experiment and theoretical and simulation studies:

1. Designing Neutralized Drift Compression for Focusing of Intense Beam Pulses in a Background Plasma, I. Kaganovich, R. Davidson, M. Dorf, E. Startsev, A. Sefkow, J. Barnard, A. Friedman, E. Lee, S. Lidia, B. G. Logan, P. Roy, P. Seidl, D. Welch

2. Progress in Beam Focusing and Compression for Target Heating and Warm Dense Matter Experiments, P. A. Seidl, A. Anders, F. M. Bieniosek, J. E. Coleman, J.-Y. Jung, M. Leitner, S. Lidia, B. G. Logan, P. Ni, D. Ogata, P. Roy, W. Waldron, J. Barnard, R. Cohen, D. Grote, E. Gilson, D. Welch

3. Application of the Reduction of Scale Range in a Lorentz Boosted Frame to the Numerical Simulation of Particle Acceleration Devices, J-L. Vay

In addition, members of HIFS-VNL presented the following 19 poster presentations to the international accelerator physics community:

1. Collective Instabilities and Beam-Plasma Interactions for an Intense Ion Beam Propagating through Background Plasma, R. Davidson, M. Dorf, I. Kaganovich, H. Qin, E. Startsev

2. Non-Commutative Courant-Snyder Theory for Coupled Transverse Dynamics of Charged Particles in Electromagnetic Focusing Lattices, H. Qin and R. Davidson

3. Generalized Kapchinskij-Vladimirskij solution for wobbling and tumbling beams in a solenoidal focusing lattice with transverse deflecting plates, H. Qin and R. Davidson

4. Calculation of Charge-Changing Cross Sections of Ions or Atoms Colliding with Fast Ions Using the Classical Trajectory Method, I. Kaganovich, R. Davidson, H. Mebane, A. Shnidman

5. Adiabatic Formation and Properties of a Quasi-Equilibrium Beam Distribution Mathced to a Periodic Focusing Lattice, M. Dorf, R. Davidson, H. Qin, E. Startsev

6. Approximate Matched Solution of Intense Charged Particle Beam Propagating through Periodic Quadrupole Focusing Lattice, E. Startsev, R. Davidson, M. Dorf 
7. Studies of the Behavior of Modified-Distribution-Function Beams on the Princeton Paul Trap Simulator Experiment, E. P. Gilson, R. C. Davidson, M. Dorf, P. Efthimion, R. Majeski, E. Startsev, H. Wang, A. Arora, M. Chung, N. Thomas

8. Development of a Li+ Alumino-Silicate Ion Source, P. Roy, A. Anders, W. Greenway, J. Kwan, S. Lidia, P. Seidl, W. Waldron

9. Commissioning Results of the Upgraded Neutralized Drift Compression Experiment, S. Lidia, P. Roy, P. Seidl, W. Waldron, E. Gilson

10. Fast Correction Optics to Reduce Chromatic Aberrations in Longitudinally Compressed Ion Beams, S. Lidia, E. Lee, D. Ogata, P. Seidl, S. Lund

11. Multi-Meter-Long Plasma Source for Heavy Ion Beam Charge Neutralization, P. Efthimion, R. Davidson, E. Gilson, B. G. Logan, P. Seidl, W. Waldron

12. A statistical study of beam centroid oscillations in a solenoid transport channel, S. M. Lund, J. Coleman, P. Seidl, C. Wootton

13. Application of the Adaptive Mesh Refinement Technique to Particle-in-Cell Simulations of Beams and Plasmas, J-L. Vay, C. Geddes, A. Friedman, D. Grote

14. Simulation of a Feedback System for the Attenuation of E-Cloud Driven Instability, J-L. Vay, J. Byrd, M. Furman, M. Venturi, J. Fox

15. Update on Electron-Cloud Simulations Using the Package WARP-POSINST, J-L Vay, C. Celata, M. Furman, M. Venturini, K. Sonnad

16. Full Electromagnetic Simulation of Free-Electron Laser Amplifier Physics via the Lorentz-Boosted Frame Approach, W. Fawley, J-L Vay

17. Investigation of Single Bunch Instabilities due to Electron Cloud Effects, $\mathrm{K}$. Sonnad, G. Rumolo, F. Zimmermann, G. Franchetti, K. Ohmi, M. Furman, J-L Vay, M. Pivi, T. Raubenheimer

18. Cyclotron Resonances in Electron Cloud Dynamics, C. Celata, M. Furman, J-L. Vay, D. P. Grote, J. Ng, M. Pivi, L. Wang

19. Simulating an acceleration schedule for NDCX II, W.M. Sharp, A. Friedman, D.P. Grote, E. Henestroza, M. Leitner, W. Waldron 